\section{Kidney \\ Blood Pressure Research}

\title{
Prognostic Cardiovascular Markers in Chronic Kidney Disease
}

\author{
Szu-Chia Chen ${ }^{a, c, d, e}$ Jiun-Chi Huang ${ }^{a, c, d, e}$ Ho-Ming Sub,c,e Yi-Wen Chiue,e \\ Jer-Ming Chang ${ }^{\mathrm{a}, \mathrm{e}}$ Shang-Jyh Hwang ${ }^{\mathrm{a}, \mathrm{e}}$ Hung-Chun Chen ${ }^{\mathrm{a}, \mathrm{e}}$
}

aDivision of Nephrology, Department of Internal Medicine, Kaohsiung Medical University Hospital, Kaohsiung Medical University, Kaohsiung; ${ }^{b}$ Division of Cardiology, Department of Internal Medicine, Kaohsiung Medical University Hospital, Kaohsiung Medical University, Kaohsiung, 'Department of Internal Medicine, Kaohsiung Municipal Hsiao-Kang Hospital, Kaohsiung Medical University, Kaohsiung, 'Graduate Institute of Clinical Medicine, College of Medicine, Kaohsiung Medical University, Kaohsiung, eFaculty of Medicine, College of Medicine, Kaohsiung Medical University, Kaohsiung, Taiwan

\section{Key Words}

Chronic kidney disease - End-stage renal disease $\cdot$ Cardiovascular markers $•$ Cardiovascular and renal outcomes

\begin{abstract}
Chronic kidney disease (CKD), including end-stage renal disease (ESRD), is a public health issue worldwide, and is associated with high rates of morbidity and mortality. In addition, cardiovascular disease is a major cause of mortality in these patients. Both traditional and nontraditional risk factors associated with CKD can lead to remodeling of the myocardium and blood vessels, thereby resulting in cardiomyopathy, atherosclerosis and arterial stiffness. This can subsequently lead to ischemic heart disease, heart failure, cardiovascular death, rapid renal progression and progression to ESRD. Identifying these risk factors to allow for aggressive preventive and interventional strategies is important for the management of patients with CKD. This aim of this review was to survey the clinical outcomes of CKD using cardiac and vascular markers including echocardiographic parameters, systolic time intervals, electrocardiography, heart rate variability, ankle-brachial index, pulse wave velocity, differences between interarm and interankle blood pressure, and vascular calcification.

\section{Introduction}

Chronic kidney disease (CKD), including end-stage renal disease (ESRD), is a global public health issue which is associated with high rates of morbidity and mortality, and cardiovascular (CV) disease is a major cause of mortality in this population [1]. This increased risk of CV disease is in part due to increased frequencies of traditional and nontraditional 


\section{Kidney Blood Pressure Research}

risk factors in patients with CKD [2]. These risk factors can induce remodeling of the myocardium and blood vessels, resulting in cardiomyopathy, atherosclerosis and arterial stiffness, and subsequently leading to ischemic heart disease, heart failure, CV death, rapid renal progression, and progression to ESRD (Fig. 1). Therefore, identifying these risk factors to allow for the implementation of aggressive preventive and interventional strategies is essential when managing patients with CKD.

Because

cardiac

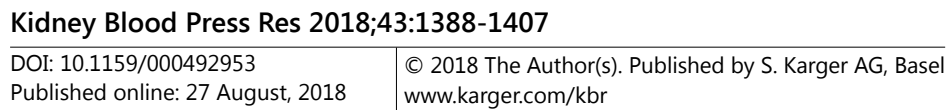

Chen et al.: Prognostic Cardiovascular Markers in CKD

dysfunction is associated with a poor prognosis in patients with renal failure and vice versa, an increasing amount of research has focused on the pathophysiological link between a failing heart and the kidneys. Cardiorenal syndrome is defined as disorders of the heart and kidneys in which dysfunction of one organ may induce dysfunction in the other [3]. Rocho et al. proposed a new classification of cardiorenal syndrome, with five subtypes reflecting primary and secondary pathophysiologies, duration of disease, and simultaneous dysfunction of the heart and kidneys secondary to the systemic disease [3].

The aim of this review was to evaluate the clinical outcomes of patients with CKD using cardiac and vascular markers including echocardiographic parameters, systolic time intervals (STIs), electrocardiography (ECG), heart rate variability (HRV), ankle-brachial index (ABI), pulse wave velocity (PWV), differences in interarm and interankle blood pressure (BP), and vascular calcification.

\section{Cardiac markers}

\section{Echocardiography parameters}

Echocardiography is the most useful imaging tool for cardiac assessment. Structural and functional abnormalities of the heart are common in patients with CKD due to pressure and volume overload [4,5]. Echocardiographic parameters including left ventricular (LV) function and structure along with left atrial (LA) size have been used to predict CV outcomes in various populations [6-8].

LV hypertrophy (LVH). (1). Association between LVH and CV outcomes. LVH is highly prevalent in patients with CKD, and it has also commonly been reported to be inappropriate $[9,10]$. LVH can be classified into concentric and eccentric subtypes, and the persistence or development of concentric geometry has been reported to have prognostic significance in hypertensive patients [11]. Silaruks et al. [8] investigated the clinical outcomes of LVH in 66 patients without diabetes undergoing peritoneal dialysis, and reported that severe LVH (left wall thickness $>1.4 \mathrm{~cm}$ ) was significantly associated with high rates of CV morbidity and mortality. The Cardiovascular Risk Reduction by Early Anemia Treatment with Epoetin Beta (CREATE) trial also found that LVH was common in patients with CKD stage 3-4, and 
that it was associated with poor CV outcomes [6]. Another study in patients with CKD stages 3-5 also found that an increased LV mass index (LVMI) was independently associated with adverse CV outcomes [12].

(2). Association between LVH and renal outcomes. Paoletti et al. [13] studied 144 patients with CKD stage 3-4 to evaluate the role of LVH in predicting progression to dialysis, and found that an increased LVMI was independently associated with progression to dialysis and the combined endpoints of dialysis or morality. The authors concluded that the same pathogenetic factors were responsible for both kidney damage and increases in LV wall thickness and internal LV dimensions. Chen et al. [14] also found that concentric LVH was significantly associated with progression to dialysis in patients with CKD stage 3-5, and concluded that patients with concentric LVH may have decreased myocardial contractility and impaired LV diastolic function [11], and that this may adversely impact renal function leading to worse renal outcomes [14]. They explained their findings by the same pathogenetic factors responsible for kidney damage and increase in both left ventricular wall thickness and internal dimension. The mechanisms of progressive renal function decline in patients with cardiac abnormalities are multi-factorial including chronic renal hypoperfusion, subclinical inflammation, endothelial dysfunction, accelerated atherosclerosis, increased renal vascular resistance, systemic neurohormonal factors, pharmacotherapies, and anemia [3].

LA diameter. Increased LA dimension has also been reported to be common among patients with CKD, and it may be associated with the subsequent development of heart failure and the risk of mortality [15].

(1). Association between LA diameter and CV outcomes. An enlarged LA has been reported to be a marker of adverse $\mathrm{CV}$ outcomes including stroke, congestive heart failure, atrial fibrillation, and mortality $[16,17]$. Pressure and volume overload can both contribute to an enlarged left atrium. Kim et al. [7] evaluated the impact of an enlarged left atrium on all-cause and CV mortality in 216 patients undergoing peritoneal dialysis, and they found that an increased LA volume index $\left(>32 \mathrm{~mL} / \mathrm{m}^{2}\right)$ could predict all-cause and CV mortality. Chen et al. also reported that a LA diameter $>4.7 \mathrm{~cm}$ was independently associated with an increased risk of CV events in patients with CKD stage 3-5 [12]. This may imply that LA enlargement can predict adverse CV outcomes in patients with CKD stage 3-5.

(2). Association between LA diameter and renal outcomes. Patients with a large left atrium may have impaired LV diastolic function [16]. Furukawa et al. [18] evaluated the impact of LA volume index on the progression to hemodialysis (HD) in 140 patients with CKD stage 4-5, and found that the LA volume index was an independent risk factor for the duration to dialysis. Chen et al. also investigated the associations between echocardiographic parameters and the rate of renal function decline, and found that LA diameter was associated with estimated glomerular filtration rate (eGFR) slope [14]. This implies that patients with impaired LV diastolic function as evidenced by an increased LA diameter may experience a rapid decline in renal function and adverse renal outcomes. Patients with an increased LA diameter may have a high volume status, thereby increasing renal efferent pressure and decreasing renal blood flow, subsequently leading to a progressive decline in renal function.

$L V$ ejection fraction (LVEF). Liu et al. reported a significant decrease in LV systolic function along with worsening renal function in patients with CKD and controls [19]. LV systolic function can be estimated conventionally using LV ejection fraction (LVEF), or by using a geometry-independent method such as midwall fractional shortening (mwFS).

(1). Association between LVEF and CV outcomes. A decrease in LV systolic function has been reported to predict poor CV outcomes in the general population and in patients with heart failure [20,21]. LV systolic dysfunction has also been reported to be an important risk factor for CV death in patients with ESRD [22]. Furthermore, patients with CKD have been reported to have a high prevalence of LV dysfunction [5], and a LVEF $<55 \%$ has been associated with an increased risk of CV events in patients with CKD stage 3-5 [12]. Hence, LV 


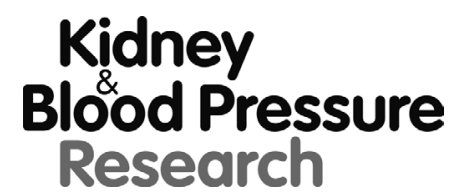

\begin{tabular}{l|l}
\hline Kidney Blood Press Res 2018;43:1388-1407 \\
\hline DOI: 10.1159/000492953 & $\begin{array}{l}\text { C } 2018 \text { The Author(s). Published by S. Karger AG, Basel } \\
\text { www.karger.com/kbr }\end{array}$ \\
\hline Published onlıne: 27 August, 2018 &
\end{tabular}

Chen et al.: Prognostic Cardiovascular Markers in CKD

systolic dysfunction appears to be a useful indicator of poor CV outcomes in patients with moderate to advanced CKD.

(2). Association between LVEF and renal outcomes. Shlipak et al. [23] found that a decreased LV systolic function was an independent predictor of a rapid decline in renal function and an annual decline in eGFR of $>3 \mathrm{ml} / \mathrm{min} / 1.73 \mathrm{~m}^{2}$ in the elderly. In their study, the baseline eGFR of the patients was $80 \mathrm{ml} / \mathrm{min} / 1.73 \mathrm{~m}^{2}$. In addition, Chen at el. also reported an association between LV systolic parameters, including LVEF and mwFS, and a rapid decline in renal function in patients with CKD stage 3-5 and a baseline eGFR of $27.3 \mathrm{ml} /$ $\mathrm{min} / 1.73 \mathrm{~m}^{2}$ [14]. This suggests that a decreased LVEF and mwFS may be useful indicators of a rapid decline in renal function in patients with moderate to advanced CKD.

The ratio of transmitral $E$ wave velocity (E) to early diastolic mitral velocity (Ea). The ratio of $E$ to Ea has been reported to be significantly associated with LV diastolic function and filling pressure [24].

(1). Association between E/Ea and CV outcomes. Previous studies have shown that E/Ea, an estimate of LV filling pressure by Doppler echocardiography, is a predictor of all-cause mortality in patients with LV systolic dysfunction and after acute myocardial infarction $[25,26]$. Another study in patients with ESRD also reported that an E/Ea $\geq 15$ could predict an increase in LV filling pressure with a sensitivity of $82 \%$ and specificity of $88 \%$, and was associated with an increased risk of mortality [27]. In addition to predicting allcause mortality in patients with ESRD, a high E/Ea has been reported to provide additional prognostic value in addition to traditional echocardiographic parameters [27, 28]. Chen et al. also found that a high E/Ea was associated with an increased risk of CV events in patients with CKD [29].

(2). Association between E/Ea and renal outcomes. A previous study evaluated the association between E/Ea and the progression of renal dysfunction in 75 patients without CKD and 92 patients with CKD with a mean eGFR of $57 \mathrm{ml} / \mathrm{min} / 1.73 \mathrm{~m}^{2}$, and found a higher $\mathrm{E} /$ Ea in the patients with a more rapid decline in renal function [30]. Chen et al. also reported an independent association between a high $\mathrm{E} / \mathrm{Ea}$ and an increased risk of starting dialysis in 356 patients with CKD with a mean eGFR of $25.7 \mathrm{ml} / \mathrm{min} / 1.73 \mathrm{~m}^{2}$ [29]. This implies that a high E/Ea ratio may lead to a high volume status, and may increase renal efferent pressure and decrease renal blood flow, subsequently leading to a progressive decline in renal function [31]. A higher preload status may also contribute to a more rapid progression to dialysis.

The ratio of observed to predicted LV mass (LVM). Various hemodynamic and metabolic disturbances have been reported to structurally and functionally affect the heart in patients with CKD [32]. In order to compensate for these disturbances, an excessive increase in LVM, a condition known as 'inappropriate LVM', is frequently noted in patients with CKD [33]. Several studies have reported the use of predicted LVM according to the sex, height, and hemodynamic load of the patients as a reference point for inappropriate LVM [10]. In other words, the appropriateness of LVM can be estimated as observed LVM/predicted LVM. A significant proportion of patients with arterial hypertension and aortic stenosis have been reported to have inappropriate LVM, and this has been reported to be a negative prognostic factor for CV outcomes [34]. In addition, inappropriate LVM has also been strongly associated with the presence and severity of CKD $[9,10]$.

(1). Association between observed/predicted LVM and CV outcomes. Inappropriate LVM clusters markers of CV risk [35, 36]. de Simone et al. [34] investigated the impact of inappropriate LVM on the CV prognosis of 294 hypertensive patients, and found that it predicted a poor CV prognosis independently of age and systolic BP. In addition, Mureddu et al. reported that an increased observed/predicted LVM was associated with an increased risk of CV events in patients with CKD stage 3-5. Taken together, these findings suggest that observed/predicted LVM may be a useful indicator of poor CV outcomes in patients with moderate to advanced CKD [37]. 


\section{Kidney Blood Pressure Research}

Kidney Blood Press Res 2018;43:1388-1407

\begin{tabular}{l|l}
\hline DOI: 10.1159/000492953 & (C) 2018 The Author(s). Published by S. Karger AG, Base
\end{tabular}

Published onlıne: 27 August, 2018

www.karger.com $/ \mathrm{kb}$

Chen et al.: Prognostic Cardiovascular Markers in CKD

(2). Association between observed/predicted LVM and renal outcomes. Nardi et al. [10] evaluated the prevalence of inappropriate LVM in patients with CKD stage 2-5 with a mean eGFR of $39 \mathrm{ml} / \mathrm{min} / 1.73 \mathrm{~m}^{2}$, and found that the patients with CKD had a higher prevalence of inappropriate LVM compared to hypertensive patients with normal renal function (52.6\% vs. $30.5 \%, p<0.001)$. Cioffi et al. [9] also investigated the relationship between inappropriate LVM and renal function in patients with a mean eGFR of $67 \mathrm{ml} / \mathrm{min} / 1.73 \mathrm{~m}^{2}$, and found an inverse relationship between observed/predicted LVM and eGFR. Chen et al. also demonstrated a significant trend of stepwise increases in observed/predicted LVM and the prevalence of inappropriate LVM corresponding to an advanced stage of CKD in patients with a mean eGFR of $25.2 \mathrm{ml} / \mathrm{min} / 1.73 \mathrm{~m}^{2}$ [37].

Global LV longitudinal systolic strain (GLS). Two dimensional (2D) speckle-tracking echocardiography has been used to accurately evaluate myocardial strain and strain rate [38]. In addition, 2D speckle-tracking echocardiography has also been used to differentiate between active and passive myocardial motion to allow for the 2D angle-independent quantification of myocardial deformation, which can more accurately reflect the systolic and diastolic performance of all myocardial segments. GLS, which can be measured from 2D speckle-tracking echocardiography, is a novel method that has recently been used to assess systolic LV function [39], and less negative GLS has been reported to be associated with an increased risk of mortality in patients undergoing HD [40].

(1). Association between GLS and CV outcomes. Evaluating LV systolic function is a fundamental part of an echocardiographic examination [41] and LVEF is the simplest and most commonly used parameter to globally assess LV function. However, the quantitative measurement of LVEF is limited by the requirement to accurately trace endocardial borders and the necessity of formulae that make assumptions with regards to the LV geometry [42]. LVEF can be used to denote global LV function but not to infer any regional differences, and reported associations between LVEF and mortality have been inconsistent $[43,44]$. In addition, LVEF measurements can be subjective, especially in cases where the endocardial border cannot be clearly visualized. LV systolic function is a complex action involving longitudinal contraction, circumferential shortening and radial thickening, and other techniques can be used in addition to or instead of LVEF, including tissue Doppler measurements of the mitral annulus and speckle-tracking echocardiography. Speckle-tracking imaging is a relatively new technique which has been used to analyze multidimensional myocardial deformations. Compared to tissue Doppler-derived strain, speckle-derived strain is easier to calculate and is not limited by angle dependency. In addition, several studies have reported that GLS can offer additional prognostic value in predicting CV outcomes in addition to LVEF in patients with renal insufficiency $[45,46]$. Even though decreases in longitudinal and radial systolic function have been reported in patients with ESRD, their LVEF may remain within normal range through preserved circumferential function. 2D speckle-tracking echocardiography has also been used to assess the severity of uremic cardiomyopathy during the early stages of the disease, and it may also be useful in patients with ESRD and preserved LVEF [40].

The ratio of $E$ to $L V$ early global diastolic strain rate (E'sr). 2D speckle-tracking echocardiography has been used to assess E'sr, and it also has been reported to be useful in assessing LV diastolic function [47]. The original purpose of E' was to evaluate regional diastolic function, and thus it is limited with regards to assessing global diastolic function with regional functional abnormalities [48]. Moreover, the inherent limitations of Dopplerbased assessments including the potential for significant errors in angle dependency with angulations $>20^{\circ}$ may also limit the use of $E^{\prime}$ in assessing early diastolic function. In contrast, E'sr, as measured from 2D speckle-tracking echocardiography, has recently been used as a novel parameter to reflect LV relaxation function [47]. E'sr can discriminate between active and passive myocardial motion, and it can be used to quantify the angle independence of 


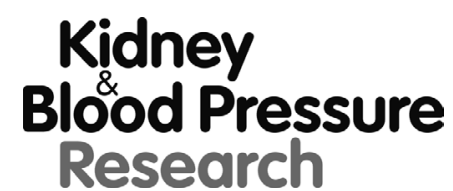

\begin{tabular}{l|l}
\hline Kidney Blood Press Res 2018;43:1388-1407 \\
\hline DOI: 10.1159/000492953 & $\begin{array}{l}\text { C } 2018 \text { The Author(s). Published by S. Karger AG, Basel } \\
\text { www.karger.com/kbr }\end{array}$ \\
\hline Published onlıne: 27 August, 2018 &
\end{tabular}

Chen et al.: Prognostic Cardiovascular Markers in CKD

myocardial deformation in 2D. Hence, E'sr may be able to reflect LV diastolic function more globally and accurately than E'.

(1). Association between $E / E$ 'sr and $C V$ outcomes. Several studies have reported that invasively-measured LV filling pressure is strongly associated with the E/E'sr ratio [49], and that the E/E'sr ratio is associated with the outcomes of patients with acute myocardial infarction [50]. In addition, a recent study reported that the E/E'sr ratio is a useful and more powerful parameter than the E/E' ratio in predicting adverse CV events in patients with atrial fibrillation [51].

(2). Association between $E / E$ 'sr and renal outcomes. Chen et al. observed that an increase in E/E'sr ratio was independently associated with an increase in progression to the renal endpoint ( $\geq 25 \%$ decline in eGFR) in patients with atrial fibrillation [52]. Moreover, they showed that the E/E'sr ratio was superior to the E/E' ratio in predicting progression to the renal endpoint, and that the E/E'sr ratio could add significant prognostic value in addition to traditional clinical and echocardiographic parameters [52]. This implies that patients with atrial fibrillation with a high E/E'sr ratio may have a high volume status, and that this may increase the renal efferent pressure and decrease renal blood flow, subsequently causing a progressive decline in renal function. A higher preload status may result in a faster deterioration in renal function, and therefore evaluating the E/E'sr ratio in patients with atrial fibrillation may allow for the identification of patients at high-risk of adverse renal outcomes.

The ratio of brachial pre-ejection period (bPEP) to brachial ejection time (bET)

STIs are an established, clinically valuable, noninvasive technique which is used to quantitatively assess cardiac performance [53]. A prolonged pre-ejection period (PEP) and shortened ejection time (ET) have been reported to be correlated with a decrease in LV systolic function [53-55]. In addition, a high correlation $(r=-0.90)$ between PEP/ET and LVEF has been reported in patients with a wide variety of heart diseases [52]. However, both PEP and ET are usually obtained from echocardiography, and thus they cannot be used to evaluate LV systolic function when echocardiography is unavailable.

The ABI-form device (Colin VP1000, Komaki, Japan) was developed to automatically and measure BP simultaneously in both arms and ankles, and to record brachial and posterior tibial artery pulse waves using an automated oscillometric method. This device allows for the simple and automatic calculation of bPEP and bET using electrocardiographic and phonocardiographic signals and brachial pressure volume waveform [56].

As a tool to determine LV systolic function and the efficacy of novel treatments to improve cardiac dysfunction, Chen et al. evaluated the correlation between brachial STIs measured from the ABI-form device and STIs measured from echocardiography. They found that brachial STIs were good alternatives to STIs obtained from echocardiography, and that they were also helpful in identifying an LVEF < 50\% [57]. They also found that although brachial and echocardiographic STIs were different, brachial STIs were useful parameters which could be easily and quickly obtained to evaluate LV systolic dysfunction.

Although $\mathrm{bPEP} / \mathrm{bET}$ can provide a simple and cheap method for detecting patients at risk of LVEF $<50 \%$ and increased LVMI [58], it cannot completely replace echocardiography. Echocardiography can yield important additional information, such as valve function, valve calcification, LV function and regional left ventricular wall motion.

Association between bPEP/bET and CV outcomes. The bPEP/bET ratio has been reported to be an independent predictor of adverse outcomes in patients with kidney disease, including CV events in patients with CKD stage 3-5 [59], and overall and CV mortality in patients receiving HD [60]. Therefore, screening patients with kidney disease using the $\mathrm{bPEP} / \mathrm{bET}$ ratio may help to identify patients at high risk of CV events [59].

Association between bPEP/bET and renal outcomes. Chen et al. studied 196 patients with CKD stage 3-5 and classified them into four groups according to median values of bPEP/ bET and brachial-ankle PWV (baPWV) as follows: group 1, bPEP/bET and baPWV below the 


\section{Kidney \\ Blood Pressure Research}

Kidney Blood Press Res 2018;43:1388-1407

\begin{tabular}{l|l}
\hline DOI: 10.1159/000492953 & (C) 2018 The Author(s). Published by S. Karger AG, Base
\end{tabular}

Published onlıne: 27 August, 2018

www.karger.com/kb

Chen et al.: Prognostic Cardiovascular Markers in CKD

median; group 2, bPEP/bET above but baPWV below the median; group 3, bPET/bET below but baPWV above the median; and group 4, bPET/bET and baPWV above the median. The decline in renal function was assessed by eGFR slope, and the renal endpoints were defined as initiating dialysis or $\geq 25 \%$ decline in eGFR. The results showed that a higher baPWV and $\mathrm{bPEP} / \mathrm{bET}$ were associated with a more rapid decline in renal function and adverse renal endpoints [61]. Classifying such patients in this manner may therefore be useful in stratifying patients at risk of a progressive decline in renal function, and this suggests possible interactions between the heart, vessels and kidneys.

\section{2 lead ECG P wave}

Echocardiography is commonly used to evaluate structural and functional abnormalities of the heart. However, its use depends on the availability of experienced operators. Twelvelead ECG is a simple and cheap noninvasive clinical tool used to access structural and functional abnormalities of the heart [62], in which the $\mathrm{P}$ wave parameter has been reported to be useful in assessing the risk of LA enlargement, LVH, and LV diastolic dysfunction [63, 64]. Furthermore, the $P$ wave has been associated with increased risks of atrial fibrillation and recurrent transient ischemic attacks $[65,66]$.

Association between $P$ wave and CV outcomes. LVH, LV diastolic dysfunction, and an enlarged diameter and volume of the left atrium may lead to changes in the hemodynamics and morphology of the left atrium, resulting in instability and heterogeneity in electrical conduction within the atrium. In turn, this can lead to a significantly increased dispersion of the $\mathrm{P}$ wave, which has been associated with overall and CV mortality in patients undergoing HD [67]. P wave dispersion may therefore reveal structural and functional abnormalities of the heart in patients undergoing HD, and may play an important role in adverse outcomes.

Association between $P$ wave and renal outcomes. Su et al. reported that an increase in $\mathrm{P}$ wave dispersion and maximum $\mathrm{P}$ wave duration were associated with progression to the renal endpoint of $\geq 25 \%$ decline in eGFR in 166 patients with a mean eGFR of $57.0 \pm 17.2$ $\mathrm{ml} / \mathrm{min} / 1.73 \mathrm{~m}^{2}$ [68]. In addition, Huang et al. also reported that an increase in $\mathrm{P}$ wave dispersion and maximum $\mathrm{P}$ wave duration were associated with progression to dialysis or death and a rapid decline in renal function in patients with CKD stage 3-5 with a mean eGFR of $26.1 \pm 14.2 \mathrm{ml} / \mathrm{min} / 1.73 \mathrm{~m}^{2}$ [67]. However, even though $\mathrm{P}$ wave parameters are a simple and cheap method to detect patients at risk of an enlarged left atrium and LV diastolic and systolic dysfunction, it cannot completely replace echocardiography.

\section{$H R V$}

HRV, a measure of variations in heart rate, has been used to assess CV autonomic neuropathy. In practice, it is defined as variations in both instantaneous heart rate and R-R intervals on ECG, and it may represent a simple and noninvasive method to assess activities of the autonomic nervous system [69]. An abnormal HRV primarily reflects dysregulation between the sympathetic and parasympathetic nervous systems. HRV frequency-domain analysis has been widely adopted to assess the function of the autonomic nervous system due to its non-invasiveness and easy accessibility.

Patients undergoing HD have been reported to exhibit a low HRV, indicating impaired autonomic function [70]. Furthermore, lower HRV has been associated with adverse CV outcomes and mortality in patients undergoing HD [70, 71], and HD itself has been proposed to improve HRV [72]. HRV can be categorized as being high-frequency (HF) and lowfrequency (LF) [69]. HF HRV is analogous to respiratory sinus arrhythmia, and it can be used to characterize vagal control of the heart rate [73]. Both vagal and sympathetic activities have been reported to contribute to LF HRV [74], and normalized LF (LF\%) and the LF/ $\mathrm{HF}$ ratio have been reported to reflect sympatho-vagal balance and sympathetic modulation [69]. 


\section{Kidney Blood Pressure Research}

Kidney Blood Press Res 2018;43:1388-1407

DOI: $10.1159 / 000492953$

Published onlıne: 27 August, 2018

(c) 2018 The Author(s). Published by S. Karger AG, Base

www.karger.com/kbr

Chen et al.: Prognostic Cardiovascular Markers in CKD

More recent measures of HRV (e.g. entropy-based measures, complexity/scale invariant/fractal measures) should be also investigated as spectral HRV measures have many limitations and their physiological interpretation is not as clear as previously thought.

$H R V$ changes before and after HD. Dialysis-induced changes in autonomic CV modulation have been shown to be comparable to changes in HRV in patients undergoing HD. Barnas et al. evaluated changes in the autonomic nervous system during HD and ultrafiltration in $26 \mathrm{HD}$ patients, and found an increase in the LF component of HRV during non-hypotensive dialysis. This is consistent with a study which evaluated the compensatory baroreflex-mediated activation of the sympathetic nervous system [75]. Zitt et al. also investigated the association between diabetes and autonomic CV regulation during HD, and in contrast to eight diabetic patients who had a blunted autonomic response, LF, HF and LF/HF increased during dialysis in nine non-diabetic patients [76]. Impaired autonomic function may be related to diabetesrelated damage in autonomic neuropathy, as some HRV parameters (HF, LF\%, LF/HF) have been reported to be increased after HD in patients without peripheral artery disease, but not in patients with peripheral artery disease [77]. This suggests that in patients with peripheral artery disease, a decrease in the compensatory increase in sympathetic and parasympathetic activity per se may enhance the risk of hemodynamic instability and further increase the risk of $\mathrm{CV}$ disease.

Association between HRV and $\triangle H R V$ with CV outcomes in HD. Reduced HRV has been reported to be a significant risk factor for overall and CV mortality in patients with ESRD [71]. Chen et al. identified that $\triangle \mathrm{HRV}$, defined as post- minus pre-HD HRV, was a risk factor for overall and CV mortality in patients with HD. Furthermore, they found that adding $\triangle H R V$ to a model consisting of various clinical parameters improved the prediction of poor outcomes [78]. Therefore, dynamic changes in HRV before and after HD may more accurately reflect impaired CV autonomic neuropathy than resting HRV prior to HD. The proposed mechanisms responsible for changes in CV variability could be decreased oxidative stress, central volume status, baroreflex arch information or increased cardiac cholinergic responsiveness [79].

\section{Vascular markers}

\section{$A B I$}

Peripheral artery occlusive disease (PAOD) is common among patients with ESRD, and it is the most common cause of amputation [80]. PAOD has also been associated with increased rates of CV mortality, morbidity, and hospitalizations in patients with ESRD [80, 81]. The ABI has been reported to be a useful marker for atherosclerosis, and an ABI $<0.9$ has been used to diagnose PAOD [82]. Moreover, an $\mathrm{ABI} \geq 1.3$ has been used to diagnose medial artery calcification (MAC) [83]. Uremia is known to promote the progression of PAOD, and high rates of PAOD and MAC are common in patients with CKD, possibly due to vascular calcification, infection, malnutrition, oxidative stress, and changes in inflammatory and coagulation pathways $[84,85]$. Furthermore, an ABI $<0.9$ has been associated with an increased rate of vascular access failure in patients undergoing $\mathrm{HD}$, suggesting that patients with severe atherosclerosis (with an $\mathrm{ABI}<0.9$ ) may be at a higher risk of developing vascular access failure [86].

The sensitivity of ABI measurements for detection of PAOD among patients with ESRD has not been tested. This technique is probably less sensitive than in the general population, because of the high prevalence of arterial calcification in this population, especially with diabetes [87]. Thus, estimates of PAOD prevalence based on ABI testing might underestimate the true prevalence of PAOD in the ESRD population.

Association between ABI progression in $H D$. Chen et al. reported yearly increases in the prevalence of $\mathrm{ABI}<0.9$ in patients undergoing $\mathrm{HD}(10.4 \%, 22.7 \%$, and $27.9 \%$, respectively; $p<0.001)$, but decreases in yearly values of ABI $(1.11 \pm 0.16,0.97 \pm 0.17$, and $0.96 \pm 0.19$, respectively; $p<0.001$ ) in 154 patients who completed 2 years of follow-up, suggesting 


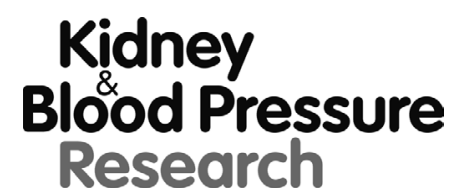

\begin{tabular}{l|l}
\hline Kidney Blood Press Res 2018;43:1388-1407 \\
\hline DOI: 10.1159/000492953 & $\begin{array}{l}\text { C } 2018 \text { The Author(s). Published by S. Karger AG, Basel } \\
\text { www.karger.com/kbr }\end{array}$ \\
\hline Published onlıne: 27 August, 2018 &
\end{tabular}

Chen et al.: Prognostic Cardiovascular Markers in CKD

increases in the yearly prevalence of PAOD and yearly decreases in $\mathrm{ABI}$ in patients undergoing HD [88]. Furthermore, the results of their longitudinal study showed that $\triangle A B I<-0.3$ was independently associated with an elevated risk of CV events in these patients [89].

Association between ABI and LVH. Atherosclerosis leads to decreased blood perfusion and increased arterial wall stiffness in the lower extremities, both of which contribute to a lower ABI and arterial distensibility, and subsequently progression to LVH [90, 91]. Conversely, LVH causes systolic and diastolic dysfunction of the left ventricle and reduces cardiac output, which further worsens blood perfusion of the extremities, promotes the progression of PAOD, and deceases the ABI. Su et al. reported higher values of LVMI and a higher prevalence of $\mathrm{LVH}$ in patients with an $\mathrm{ABI}<0.9$ and $\geq 1.3$ compared to those with an $\mathrm{ABI}$ of $\geq 0.9$ and $<1.3$, suggesting that an abnormally low or high ABI is associated with LVMI [92]. In addition, Ix et al. [93] evaluated the association between a high ABI and LVMI in 4972 participants without clinical CV disease in the MESA (Multi-Ethic Study of Atherosclerosis) Study, and found a significant association between an abnormally low or high ABI and higher LVMI. Therefore, a higher LVM may be involved in the association between a high ABI and poor CV prognosis.

Association between ABI and CV outcomes. Ono et al. [87] investigated the association between all-cause and CV mortality and ABI in HD patients, and found that an abnormal $\mathrm{ABI}$ predicted poor survival. In addition, compared to the patients with $1.1 \leq \mathrm{ABI}<1.3$, the hazard ratios of patients with an $\mathrm{ABI}<0.9, \geq 0.9$ to $<1.0$, and $\geq 1.0$ to $<1.1$ for all-cause mortality were $4.04,3.24$, and 1.92 , respectively. Therefore, the risk of all-cause mortality may increase with a decrease in ABI. An ABI > 1.3 has also been associated with increases in both overall and CV mortality in patients undergoing HD and patients with CKD [94].

There is growing evidence that dialysis process or uremia itself promotes PAOD progression [95]. Vascular calcification caused by alterations in the metabolism of calcium, phosphate, and parathyroid hormone, inflammatory and coagulation pathways alterations, oxidative stress, or hyperhomocysteinemia was a possible cause of PAOD progression in patients with uremia [84]. In addition, another factors, such as fluid overload, alterations in the renin-angiotensin-aldosterone system and endothelin system, malnutrition, infection, uremic toxins, and insulin resistance, might also contribute to atherosclerosis in patients with advanced renal failure [96].

\section{PWV}

As discussed in section 2.2, an ABI-form device can be used to easily obtain the baPWV, which has been reported to be a good marker of arterial stiffness [64]. Even though several parameters can be used to assess arterial stiffness, the gold standard non-invasive method is carotid-femoral PWV [97], which has been reported to directly reflect aortic PWV [98]. In comparison, baPWV is a composite measure of several arterial segments, and some of these segments will be prone to arteriosclerosis alone (brachial and distal arteries), whereas others will be prone to both atherosclerosis and arteriosclerosis (aorta and femoral arteries). Therefore, carotid-femoral PWV may be more reliable than baPWV in reflecting aortic PWV. However, Tanaka et al. reported a strong correlation between carotid-femoral PWV and baPWV in 2287 patients $(\mathrm{r}=0.73, p<0.001)$, and they also found similar associations between carotid-femoral PWV and baPWV and CV disease risk factors and clinical events [99]. In addition, Yamashina et al. reported a strong correlation between baPWV and aortic PWV derived from an invasive method in 41 patients $(r=0.87, p<0.01$ ) [56]. Therefore, it appears to be reasonable to use baPWV as a marker of arterial stiffness.

Association between baPWV and LVH. Arterial stiffness is caused by hypertrophy and atherosclerosis in capacitance arteries, resulting in higher PWV and changes in pressure waveform and increases in systolic and pulse pressure. Changes in wave reflections and increased stiffness have also been reported to contribute to LVH [91]. Moreover, previous studies have reported a positive correlation between PWV, a marker of arterial stiffness, and increases in LVMI and LVH [100-102]. 


\section{Kidney Blood Pressure Research}

Kidney Blood Press Res 2018;43:1388-1407

\begin{tabular}{l|l}
\hline DOI: 10.1159/000492953 & (C) 2018 The Author(s). Published by S. Karger AG, Base
\end{tabular}

Published onlıne: 27 August, 2018

www.karger.com/kb

Chen et al.: Prognostic Cardiovascular Markers in CKD

Association between unequal baPWV and CV outcomes. Hatsuda et al. reported that arterial stiffness in different regions may affect CV disease differently, and that arterial stiffening did not occur uniformly in all arterial regions in patients with ischemic heart disease [103]. This imbalance in arterial stiffness has been associated with the risk of CV events, and an $\mathrm{ABI}<0.9$, high baPWV, and high LVMI have been independently associated with large differences in bilateral baPWV [104]. Furthermore, differences in bilateral baPWV have also been associated with an increased risk of CV and overall mortality in patients undergoing HD [105].

Association between baPWV and renal outcomes. Previous studies have reported an association between a decrease in eGFR and increased arterial stiffness in patients with CKD [106-108]. In addition, other longitudinal studies using different methods to measure arterial stiffness have reported that increased arterial stiffness was an independent predictor of a deterioration in renal function in patients with CKD [109-111]. Takenaka et al. investigated the relationship between augmentation index and annual rate of decline in creatinine clearance in 41 patients with CKD without diabetes, and found that a higher basal augmentation index measured from radial artery waveforms resulted in a greater annual decline in creatinine clearance [111]. In addition, Taal et al. investigated the effect of markers of vascular disease on the risk of progression to dialysis in 35 patients with CKD stage 4 and 5 , and identified augmentation index and radial-dorsalis pedis PWV, both markers of arterial stiffness, to be risk factors for progression to dialysis [110]. Ford et al. also investigated the longitudinal relationship between changes in renal function and markers of aortic stiffness in 120 patients with CKD stage 3 and 4, and found that aortic PWV was independently associated with the rate of decline in renal function. Moreover, they also found that aortic stiffness was associated with reaching combined endpoints of commencing dialysis or a $\geq$ $25 \%$ decline in eGFR [109]. Chen et al. also reported an association between baPWV and deterioration in renal function, including a more rapid decline in eGFR and an increased risk of progression to dialysis or death in 145 patients with CKD stage 3 to 5 and a baseline eGFR level of $29.9 \mathrm{ml} / \mathrm{min} / 1.73 \mathrm{~m}^{2}$ [112]. Although the exact mechanisms for this association are unclear, it is possible that an increase in arterial stiffness may result in a higher systemic BP in the glomerular capillaries and that this then exacerbates glomerular hypertension, which is a major factor related to progressive renal damage.

\section{$B P$ in the four limbs}

Interarm BP differences. A difference in BP between arms is frequently encountered in various populations [113]. This phenomenon is known as "interarm difference", and it was first recognized more than 100 years ago. Current guidelines for the management of hypertension suggest that BP should be initially measured in both arms as patients may have large differences between them, and that the arm with the higher value should then be used for subsequent measurements [114]. Being aware of the presence of an interarm difference is vital for an accurate diagnosis, and to allow for the appropriate management of hypertension.

(1). Association between differences in interarm BP and CV comorbidities, Several studies have reported a strong association between a difference in systolic BP of $\geq 10 \mathrm{mmHg}$ and subclavian stenosis, peripheral vascular disease, and pre-existing coronary artery disease [115]. In addition, other studies have reported a strong association between an interarm difference of $\geq 10 \mathrm{mmHg}$ in systolic BP and increased CV and all-cause mortality [116-118]. Moreover, Clark et al. reported an increased risk of $\mathrm{CV}$ and overall mortality in patients with a difference of $\geq 10 \mathrm{mmHg}$ in systolic BP compared to those with a difference of $<10$ $\mathrm{mmHg}$ [118]. Furthermore, Chen et al. demonstrated an association among an $\mathrm{ABI}<0.9$, high baPWV, high LVMI and a difference in interarm systolic BP of $\geq 10 \mathrm{mmHg}$. Therefore, the presence of a difference in interarm systolic BP may provide a simple method to detect patients at an increased risk of atherosclerosis and LVH [119]. 


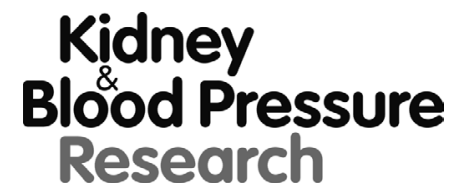

\begin{tabular}{l|l}
\hline Kidney Blood Press Res 2018;43:1388-1407 \\
\hline DOI: 10.1159/000492953 & $\begin{array}{l}\text { c } 2018 \text { The Author(s). Published by S. Karger AG, Basel } \\
\text { www.karger.com/kbr }\end{array}$ \\
\hline Published onlıne: 27 August, 2018 &
\end{tabular}

Chen et al.: Prognostic Cardiovascular Markers in CKD

Interankle BP differences. Blood pressure in the ankles is usually measured in conjunction with that in the arms to calculate the ABI. Current technology provides for the simultaneous measurement of the BP in all four limbs [56], and this may allow for a comprehensive evaluation of differences in BP between the four limbs, including differences in the ABI and interarm and interankle BP. Sheng et al. found that an interankle systolic BP difference of $\geq 15 \mathrm{mmHg}$ or $\geq 10 \mathrm{mmHg}$ could predict mortality in the elderly, and that this association remained significant after excluding those with an ABI $<0.9$ [120].

(1). Association between differences in interankle BP and CV outcomes in HD. Measuring $\mathrm{BP}$ in an arm with blood access is inappropriate in patients undergoing HD. Chen et al. found that a difference in systolic BP of $\geq 15 \mathrm{mmHg}$ or diastolic BP of $\geq 10 \mathrm{mmHg}$ between ankles was associated with atherosclerosis and an increased risk of overall and CV mortality in HD patients [121]. Furthermore, this association remained significant even after adjusting for the atherosclerotic factors of an $\mathrm{ABI}<0.9$ and baPWV. This suggests that non-atherosclerotic mechanisms may be responsible for the association between the difference in interankle BP and mortality.

(2). Association between differences in interankle BP and renal outcomes in CKD. Using a simultaneous measurement technique, Chen et al. found an association between an increase in interankle systolic BP and a low ABI and high baPWV. Furthermore, this difference was associated with rapid renal function progression and progression to renal endpoints of $\mathrm{a} \geq$ $25 \%$ decline in eGFR and commencing dialysis in patients with CKD stage 3-5, whereas no association was found with a difference in interarm systolic BP [122]. This finding implies that a difference in interankle BP may be a useful and stronger predictor of progression to renal endpoints than a difference in interarm BP in patients with CKD. Sheng et al. showed that a difference in interankle systolic BP could be used to predict both overall and CV mortality, whereas a difference in interarm systolic BP could predict only overall but not CV mortality [120]. This suggests that a difference in interankle systolic BP may provide additional prognostic value than a difference in interarm systolic BP. A possible explanation for this finding is that the circulatory burden from the heart to the ankles is greater than that from the heart to the arms.

\section{Vascular calcification}

Patients with ESRD have a higher prevalence of vascular calcification than the general population, and $80-90 \%$ of patients with ESRD have been reported to have some degree of vascular calcification [98]. Vascular calcification has been shown to be a predictive factor against CV morbidity and mortality in these patients [123], and it can be assessed using computed tomography (CT), ultrasonography and X-rays [124, 125]. The known risk factors for vascular calcification are increasing age, dialysis, hypertension, diabetes, dyslipidemia, inflammation, malnutrition, oxidative stress, hyperphosphatemia and elevated calciumphosphate product [126], all of which are frequently noted in ESRD population.

Although cardiac CT is very accurate and a truly quantitative method to assess the extent of CV calcification, it is expensive and requires exposing the patients to radiation. In contrast, aortic arch calcification (AoAC) score is a simple non-invasive tool that can be used to semi-quantitatively evaluate AoAC on chest radiography. In addition, it has been reported to be strongly associated with the volume of AoAC as determined by multidetector CT [127]. Nevertheless, despite this strong association, cardiac CT can more accurately and quantitatively evaluate the extent of CV calcification than plain radiography. In addition, plain radiography is not sensitive enough to detect early-stage vascular calcification.

(1).AoAC in HD. The AoAC as determined from chest radiography reflects the magnitude of AoAC as a whole. Moreover, it has been shown to be associated with CV and all-cause mortality in patients with ESRD [128, 129]. Furthermore, coronary artery calcium score, aorta calcium score and AoAC volume as measured on CT have also been reported to be independently associated with arterial stiffening, LVH and diastolic dysfunction $[124,130]$. The severity of AoAC has also been associated with a high baPWV and cardiothoracic ratio [131]. The exact 


\section{Kidney \\ Blood Pressure \\ Research}

mechanisms responsible for the association between AoAC and arterial stiffness have yet to be completely elucidated, however they are thought to involve structural changes within the media and vascular calcification $[132,133]$.

(2).

Association

between AoAC and ABI with $C V$ outcomes in $H D$. An et al. [134] found that a high vascular calcification score obtained from plain radiographs of the feet was associated with a high prevalence of atherosclerotic calcified plaques in femoral and popliteal arteries as evaluated using Doppler ultrasonography in pre-dialysis, HD and peritoneal dialysis patients. In addition, Adragao et al. [135] reported an association between vascular calcification score in the central arteries and an $\mathrm{ABI}<0.9$ in patients undergoing HD. Moreover, Chen et al. found that a higher AoAC score as measured from plain chest X-rays was associated with a lower $\mathrm{ABI}$ and higher prevalence of $\mathrm{ABI}<0.95$. The association between AoAC score calculated from plain X-rays and $\mathrm{ABI}$ emphasizes the relationship between AoAC and the extent of atherosclerosis in peripheral arteries. Furthermore, a combination of low $\mathrm{ABI}$ and high AoAC has been associated with increased overall and CV mortality in patients undergoing HD [136].

(3). Association between AoAC and cardiothoracic ratio and renal outcomes in CKD. AoAC has been associated with cardiomegaly [131]. In addition, vascular calcification has been shown to induce arterial wall stiffness and reduce vascular compliance, and this has been associated with increased LV afterload and hypertrophy [137]. Furthermore, Li et al. investigated the association between AoAC and cardiomegaly and renal function progression in patients with CKD stage 3-5, and found that the coexistence of AoAC and cardiomegaly was associated with a more rapid decline in eGFR [138]. This suggests that AoAC is associated with cardiomegaly, and this it may be a useful parameter to predict adverse renal outcomes.

\section{Conclusion}

CV diseases are common in patients with CKD, and CKD is a major risk factor for CV diseases. Many traditional and nontraditional risk factors also contribute to CV diseases. Functional and structural cardiac abnormalities, high bPEP/bET, high $\mathrm{P}$ wave dispersion on 12 lead ECG, low HRV, $\triangle \mathrm{HRV}, \mathrm{ABI}<0.9$ or $>1.3$, high PWV, four limb BP difference and vascular calcification may play important roles in CV and renal prognosis in patients with CKD (Fig. 2). Therefore, it is important for physicians to recognize the patients at risk and implement early prevention and treatment strategies. 


\section{Kidney \\ Blood Pressure Research}

Chen et al.: Prognostic Cardiovascular Markers in CKD

\section{Acknowledgements}

The research presented in this article is supported by the grants from the Ministry of Science and Technology (MOST 106-2314-B-037 -052), and Kaohsiung Municipal HsiaoKang Hospital (kmhk-106-003), Kaohsiung Medical University, Kaohsiung, Taiwan.

\section{Disclosure Statement}

There is no conflict of interest in the information contained in the manuscript.

\section{References}

1 Go AS, Chertow GM, Fan D, McCulloch CE, Hsu CY: Chronic kidney disease and the risks of death, cardiovascular events, and hospitalization. N Engl J Med 2004;351:1296-1305.

2 Menon V, Sarnak MJ: The epidemiology of chronic kidney disease stages 1 to 4 and cardiovascular disease: A high-risk combination. Am J Kidney Dis 2005;45:223-232.

3 Ronco C: Cardiorenal syndromes: Definition and classification. Contrib Nephrol 2010;164:33-38.

4 Paoletti E, Bellino D, Cassottana P, Rolla D, Cannella G: Left ventricular hypertrophy in nondiabetic predialysis ckd. Am J Kidney Dis 2005;46:320-327.

5 Stewart GA, Gansevoort RT, Mark PB, Rooney E, McDonagh TA, Dargie HJ, Stuart R, Rodger C, Jardine AG: Electrocardiographic abnormalities and uremic cardiomyopathy. Kidney Int 2005;67:217-226.

-6 Eckardt KU, Scherhag A, Macdougall IC, Tsakiris D, Clyne N, Locatelli F, Zaug MF, Burger HU, Drueke TB: Left ventricular geometry predicts cardiovascular outcomes associated with anemia correction in ckd. J Am Soc Nephrol 2009;20:2651-2660.

7 Kim SJ, Han SH, Park JT, Kim JK, Oh HJ, Yoo DE, Yoo TH, Kang SW, Choi KH: Left atrial volume is an independent predictor of mortality in CAPD patients. Nephrol Dial Transplant 2011;26:3732-3739.

8 Silaruks S, Sirivongs D, Chunlertrith D: Left ventricular hypertrophy and clinical outcome in capd patients. Perit Dial Int 2000;20:461-466.

-9 Cioffi G, Tarantini L, Frizzi R, Stefenelli C, Russo TE, Selmi A, Toller C, Furlanello F, de Simone G: Chronic kidney disease elicits excessive increase in left ventricular mass growth in patients at increased risk for cardiovascular events. J Hypertens 2011;29:565-573.

10 Nardi E, Palermo A, Mule G, Cusimano P, Cottone S, Cerasola G: Left ventricular hypertrophy and geometry in hypertensive patients with chronic kidney disease. J Hypertens 2009;27:633-641.

11 Muiesan ML, Salvetti M, Monteduro C, Bonzi B, Paini A, Viola S, Poisa P, Rizzoni D, Castellano M, AgabitiRosei E: Left ventricular concentric geometry during treatment adversely affects cardiovascular prognosis in hypertensive patients. Hypertension 2004;43:731-738.

12 Chen SC, Chang JM, Liu WC, Huang JC, Tsai JC, Lin MY, Su HM, Hwang SJ, Chen HC: Echocardiographic parameters are independently associated with increased cardiovascular events in patients with chronic kidney disease. Clin J Am Soc Nephrol 2012;27:1064-1070.

-13 Paoletti E, Bellino D, Gallina AM, Amidone M, Cassottana P, Cannella G: Is left ventricular hypertrophy a powerful predictor of progression to dialysis in chronic kidney disease? Nephrol Dial Transplant 2011;26:670-677.

$\checkmark 14$ Chen SC, Su HM, Hung CC, Chang JM, Liu WC, Tsai JC, Lin MY, Hwang SJ, Chen HC: Echocardiographic parameters are independently associated with rate of renal function decline and progression to dialysis in patients with chronic kidney disease. Clin J Am Soc Nephrol 2011;6:2750-2758.

15 London GM: Left ventricular alterations and end-stage renal disease. Nephrol Dial Transplant 2002;17:2936.

16 Abhayaratna WP, Seward JB, Appleton CP, Douglas PS, Oh JK, Tajik AJ, Tsang TS: Left atrial size: Physiologic determinants and clinical applications. J Am Coll Cardiol 2006;47:2357-2363. 


\section{Kidney \\ Blood Pressure Research}

Chen et al.: Prognostic Cardiovascular Markers in CKD

17 Kizer JR, Bella JN, Palmieri V, Liu JE, Best LG, Lee ET, Roman MJ, Devereux RB: Left atrial diameter as an independent predictor of first clinical cardiovascular events in middle-aged and elderly adults: The strong heart study (shs). Am Heart J 2006;151:412-418.

18 Furukawa M, Io H, Tanimoto M, Hagiwara S, Horikoshi S, Tomino Y: Predictive factors associated with the period of time before initiation of hemodialysis in ckd stages 4 and 5. Nephron Clin Pract 2011;117:c341347.

19 Liu YW, Su CT, Huang YY, Yang CS, Huang JW, Yang MT, Chen JH, Tsai WC: Left ventricular systolic strain in chronic kidney disease and hemodialysis patients. Am J Nephrol 2011;33:84-90.

20 Wang TJ, Levy D, Benjamin EJ, Vasan RS: The epidemiology of "asymptomatic" left ventricular systolic dysfunction: Implications for screening. Ann Intern Med 2003;138:907-916.

-21 Wong M, Staszewsky L, Latini R, Barlera S, Glazer R, Aknay N, Hester A, Anand I, Cohn JN: Severity of left ventricular remodeling defines outcomes and response to therapy in heart failure: Valsartan heart failure trial (val-heft) echocardiographic data. J Am Coll Cardiol 2004;43:2022-2027.

-22 Foley RN, Parfrey PS, Kent GM, Harnett JD, Murray DC, Barre PE: Serial change in echocardiographic parameters and cardiac failure in end-stage renal disease. J Am Soc Nephrol 2000;11:912-916.

23 Shlipak MG, Katz R, Kestenbaum B, Fried LF, Siscovick D, Sarnak MJ: Clinical and subclinical cardiovascular disease and kidney function decline in the elderly. Atherosclerosis 2009;204:298-303.

24 Khouri SJ, Maly GT, Suh DD, Walsh TE: A practical approach to the echocardiographic evaluation of diastolic function. J Am Soc Echocardiogr 2004;17:290-297.

25 Hillis GS, Moller JE, Pellikka PA, Gersh BJ, Wright RS, Ommen SR, Reeder GS, Oh JK: Noninvasive estimation of left ventricular filling pressure by e/e' is a powerful predictor of survival after acute myocardial infarction. J Am Coll Cardiol 2004;43:360-367.

-26 Wang M, Yip G, Yu CM, Zhang Q, Zhang Y, Tse D, Kong SL, Sanderson JE: Independent and incremental prognostic value of early mitral annulus velocity in patients with impaired left ventricular systolic function. J Am Coll Cardiol 2005; 45:272-277.

-27 Sharma R, Pellerin D, Gaze DC, Mehta RL, Gregson H, Streather CP, Collinson PO, Brecker SJ: Mitral peak doppler e-wave to peak mitral annulus velocity ratio is an accurate estimate of left ventricular filling pressure and predicts mortality in end-stage renal disease. J Am Soc Echocardiogr 2006;19:266-273.

28 Wang AY, Wang M, Lam CW, Chan IH, Zhang Y, Sanderson JE: Left ventricular filling pressure by doppler echocardiography in patients with end-stage renal disease. Hypertension 2008;52:107-114.

29 Chen SC, Chang JM, Tsai YC, Huang JC, Chen LI, Su HM, Hwang SJ, Chen HC: Ratio of transmitral e-wave velocity to early diastole mitral annulus velocity with cardiovascular and renal outcomes in chronic kidney disease. Nephron Clin Pract 2013;123:52-60.

-30 Chen SC, Lin TH, Hsu PC, Chang JM, Lee CS, Tsai WC, Su HM, Voon WC, Chen HC: Impaired left ventricular systolic function and increased brachial-ankle pulse-wave velocity are independently associated with rapid renal function progression. Hypertens Res 2011;34:1052-1058.

-31 Bock JS, Gottlieb SS: Cardiorenal syndrome: New perspectives. Circulation 2010;121:2592-2600.

-32 Veves A, Akbari CM, Primavera J, Donaghue VM, Zacharoulis D, Chrzan JS, DeGirolami U, LoGerfo FW, Freeman R: Endothelial dysfunction and the expression of endothelial nitric oxide synthetase in diabetic neuropathy, vascular disease, and foot ulceration. Diabetes 1998;47:457-463.

-33 Palmieri V, de Simone G, Roman MJ, Schwartz JE, Pickering TG, Devereux RB: Ambulatory blood pressure and metabolic abnormalities in hypertensive subjects with inappropriately high left ventricular mass. Hypertension 1999;34:1032-1040.

-34 de Simone G, Palmieri V, Koren MJ, Mensah GA, Roman MJ, Devereux RB: Prognostic implications of the compensatory nature of left ventricular mass in arterial hypertension. J Hypertens 2001;19:119-125.

35 de Simone G, Kitzman DW, Palmieri V, Liu JE, Oberman A, Hopkins PN, Bella JN, Rao DC, Arnett DK, Devereux RB: Association of inappropriate left ventricular mass with systolic and diastolic dysfunction: The hypergen study. Am J Hypertens 2004;17:828-833.

-36 Mureddu GF, Pasanisi F, Palmieri V, Celentano A, Contaldo F, de Simone G: Appropriate or inappropriate left ventricular mass in the presence or absence of prognostically adverse left ventricular hypertrophy. J Hypertens 2001;19:1113-1119. 


\section{Kidney \\ Blood Pressure Research}

Chen et al.: Prognostic Cardiovascular Markers in CKD

37 Chen SC, Chang JM, Liu WC, Chen YY, Chen LI, Huang JC, Yang TK, Su HM, Chen HC: The ratio of observed to predicted left ventricular mass is independently associated with increased cardiovascular events in patients with chronic kidney disease. Hypertens Res 2012;35:832-838.

-38 Mor-Avi V, Lang RM, Badano LP, Belohlavek M, Cardim NM, Derumeaux G, Galderisi M, Marwick T, Nagueh SF, Sengupta PP, Sicari R, Smiseth OA, Smulevitz B, Takeuchi M, Thomas JD, Vannan M, Voigt JU, Zamorano JL: Current and evolving echocardiographic techniques for the quantitative evaluation of cardiac mechanics: Ase/eae consensus statement on methodology and indications endorsed by the japanese society of echocardiography. J Am Soc Echocardiogr 2011;24:277-313.

-39 Reisner SA, Lysyansky P, Agmon Y, Mutlak D, Lessick J, Friedman Z: Global longitudinal strain: A novel index of left ventricular systolic function. J Am Soc Echocardiogr 2004;17:630-633.

$\checkmark 40$ Altekin RE, Kucuk M, Yanikoglu A, Karakas MS, Er A, Ozel D, Ermis C, Demir I: Evaluation of the left ventricular regional function using two-dimensional speckle tracking echocardiography in patients with end-stage renal disease with preserved left ventricular ejection fraction. Acta Cardiol 2012;67:681-691.

41 Cheitlin MD, Armstrong WF, Aurigemma GP, Beller GA, Bierman FZ, Davis JL, Douglas PS, Faxon DP, Gillam LD, Kimball TR, Kussmaul WG, Pearlman AS, Philbrick JT, Rakowski H, Thys DM: Acc/aha/ase 2003 guideline update for the clinical application of echocardiography--summary article: A report of the american college of cardiology/american heart association task force on practice guidelines (acc/aha/ase committee to update the 1997 guidelines for the clinical application of echocardiography). J Am Coll Cardiol 2003;42:954-970.

42 Marwick TH: Should we be evaluating the ventricle or the myocardium? Advances in tissue characterization. J Am Soc Echocardiogr 2004;17:168-172.

43 Gottdiener JS, McClelland RL, Marshall R, Shemanski L, Furberg CD, Kitzman DW, Cushman M, Polak J, Gardin JM, Gersh BJ, Aurigemma GP, Manolio TA: Outcome of congestive heart failure in elderly persons: Influence of left ventricular systolic function. The cardiovascular health study. Ann Intern Med 2002;137:631-639.

44 Curtis JP, Sokol SI, Wang Y, Rathore SS, Ko DT, Jadbabaie F, Portnay EL, Marshalko SJ, Radford MJ, Krumholz HM: The association of left ventricular ejection fraction, mortality, and cause of death in stable outpatients with heart failure. J Am Coll Cardiol 2003;42:736-742.

45 Krishnasamy R, Isbel NM, Hawley CM, Pascoe EM, Leano R, Haluska BA, Stanton T: The association between left ventricular global longitudinal strain, renal impairment and all-cause mortality. Nephrol Dial Transplant 2014;29:1218-1225.

46 Liu YW, Su CT, Sung JM, Wang SP, Su YR, Yang CS, Tsai LM, Chen JH, Tsai WC: Association of left ventricular longitudinal strain with mortality among stable hemodialysis patients with preserved left ventricular ejection fraction. Clin J Am Soc Nephrol 2013;8:1564-1574.

47 Kusunose K, Yamada H, Nishio S, Tomita N, Hotchi J, Bando M, Niki T, Yamaguchi K, Taketani Y, Iwase T, Soeki T, Wakatsuki T, Sata M: Index-beat assessment of left ventricular systolic and diastolic function during atrial fibrillation using myocardial strain and strain rate. J Am Soc Echocardiogr 2012;25:953-959.

-48 Hsiao SH, Chiou KR, Lin KL, Lin SK, Huang WC, Kuo FY, Cheng CC, Liu CP: Left atrial distensibility and e/e' for estimating left ventricular filling pressure in patients with stable angina. -a comparative echocardiography and catheterization study. Circ J 2011;75:1942-1950.

\$9 Kimura K, Takenaka K, Ebihara A, Okano T, Uno K, Fukuda N, Ando J, Fujita H, Morita H, Yatomi Y, Nagai R: Speckle tracking global strain rate e/e' predicts lv filling pressure more accurately than traditional tissue doppler e/e'. Echocardiography 2012;29:404-410.

-50 Ersboll M, Andersen MJ, Valeur N, Mogensen UM, Fahkri Y, Thune JJ, Moller JE, Hassager C, Sogaard P, Kober L: Early diastolic strain rate in relation to systolic and diastolic function and prognosis in acute myocardial infarction: A two-dimensional speckle-tracking study. Eur Heart J 2014;35:648-656.

51 Su HM, Lin TH, Hsu PC, Lee WH, Chu CY, Lee CS, Voon WC, Lai WT, Sheu SH: Global left ventricular longitudinal systolic strain as a major predictor of cardiovascular events in patients with atrial fibrillation. Heart 2013;99:1588-1596.

52 Chen SC, Lee WH, Hsu PC, Lee CS, Lee MK, Yen HW, Lin TH, Voon WC, Lai WT, Sheu SH, Su HM: Association of the ratio of early mitral inflow velocity to the global diastolic strain rate with a rapid renal function decline in atrial fibrillation. PloS One 2016;11:e0147446. 


\section{Kidney \\ Bloód Pressure Research}

Chen et al.: Prognostic Cardiovascular Markers in CKD

53 Lewis RP, Rittogers SE, Froester WF, Boudoulas H: A critical review of the systolic time intervals. Circulation 1977;56:146-158.

54 Garrard CL Jr, Weissler AM, Dodge HT: The relationship of alterations in systolic time intervals to ejection fraction in patients with cardiac disease. Circulation 1970;42:455-462.

-55 Veyrat C, Larrazet F, Pellerin D: Renewed interest in preejectional isovolumic phase: New applications of tissue doppler indexes: Implications to ventricular dyssynchrony. Am J Cardiol 2005;96:1022-1030.

-56 Yamashina A, Tomiyama H, Takeda K, Tsuda H, Arai T, Hirose K, Koji Y, Hori S, Yamamoto Y: Validity, reproducibility, and clinical significance of noninvasive brachial-ankle pulse wave velocity measurement. Hypertens Res 2002;25:359-364.

57 Su HM, Lin TH, Hsu PC, Chu CY, Lee WH, Chen SC, Lee CS, Voon WC, Lai WT, Sheu SH: A comparison between brachial and echocardiographic systolic time intervals. PloS One 2013;8:e55840.

58 Chen SC, Chang JM, Liu WC, Tsai JC, Chen LI, Lin MY, Hsu PC, Lin TH, Su HM, Hwang SJ, Chen HC: Significant correlation between ratio of brachial pre-ejection period to ejection time and left ventricular ejection fraction and mass index in patients with chronic kidney disease. Nephrol Dial Transplant 2011;26:18951902.

59 Chen SC, Chang JM, Tsai JC, Lin TH, Hsu PC, Su HM, Voon WC, Hwang SJ, Chen HC: A systolic parameter defined as the ratio of brachial pre-ejection period to brachial ejection time predicts cardiovascular events in patients with chronic kidney disease. Cir J 2010;74:2206-2210.

60 Chen SC, Chang JM, Tsai JC, Hsu PC, Lin TH, Su HM, Voon WC, Hwang SJ, Chen HC: A new systolic parameter defined as the ratio of brachial pre-ejection period to brachial ejection time predicts overall and cardiovascular mortality in hemodialysis patients. Hypertens Res 2010;33:492-498.

61 Su HM, Lin TH, Hsu PC, Chu CY, Lee WH, Chen SC, Lee CS, Voon WC, Lai WT, Sheu SH: Impact of systolic time intervals on the relationship between arterial stiffness and left ventricular hypertrophy. Atherosclerosis 2012;223:171-176.

-62 Alpert MA, Munuswamy K: Electrocardiographic diagnosis of left atrial enlargement. Arch Intern Med 1989;149:1161-1165.

63 Birkbeck JP, Wilson DB, Hall MA, Meyers DG: P-wave morphology correlation with left atrial volumes assessed by 2-dimensional echocardiography. J Electrocardiol 2006;39:225-229.

64 Gunduz H, Binak E, Arinc H, Akdemir R, Ozhan H, Tamer A, Uyan C: The relationship between p wave dispersion and diastolic dysfunction. Tex Heart Inst J 2005;32:163-167.

65 Koz C, Uzun M, Yokusoglu M, Ulas UH, Baysan O, Genc C, Cansel M, Isik E: Echocardiographic, electrocardiographic, and clinical correlates of recurrent transient ischemic attacks: A follow-up study. South Med J 2008;101:246-251.

66 Magnani JW, Johnson VM, Sullivan LM, Gorodeski EZ, Schnabel RB, Lubitz SA, Levy D, Ellinor PT, Benjamin EJ: $\mathrm{P}$ wave duration and risk of longitudinal atrial fibrillation in persons $>/=60$ years old (from the framingham heart study). Am J Cardiol 2011;107:917-921.e1.

67 Huang JC, Wei SY, Chen SC, Chang JM, Hung CC, Su HM, Hwang SJ, Chen HC: P wave dispersion and maximum p wave duration are associated with renal outcomes in chronic kidney disease. PloS One 2014;9:e101962.

68 Su HM, Tsai WC, Lin TH, Hsu PC, Lee WH, Lin MY, Chen SC, Lee CS, Voon WC, Lai WT, Sheu SH: P wave dispersion and maximum $\mathrm{p}$ wave duration are independently associated with rapid renal function decline. PloS One 2012;7:e42815.

69 Heart rate variability: Standards of measurement, physiological interpretation and clinical use. Task force of the european society of cardiology and the north american society of pacing and electrophysiology. Circulation 1996;93:1043-1065.

70 Fukuta H, Hayano J, Ishihara S, Sakata S, Mukai S, Ohte N, Ojika K, Yagi K, Matsumoto H, Sohmiya S, Kimura G: Prognostic value of heart rate variability in patients with end-stage renal disease on chronic haemodialysis. Nephrol Dial Transplant 2003;18:318-325.

71 Oikawa K, Ishihara R, Maeda T, Yamaguchi K, Koike A, Kawaguchi H, Tabata Y, Murotani N, Itoh H: Prognostic value of heart rate variability in patients with renal failure on hemodialysis. Int J Cardiol 2009;131:370377. 


\section{Kidney \\ Blood Pressure Research}

Chen et al.: Prognostic Cardiovascular Markers in CKD

72 Mylonopoulou M, Tentolouris N, Antonopoulos S, Mikros S, Katsaros K, Melidonis A, Sevastos N, Katsilambros N: Heart rate variability in advanced chronic kidney disease with or without diabetes: Midterm effects of the initiation of chronic haemodialysis therapy. Nephrol Dial Transplant 2010;25:37493754.

-73 Fouad FM, Tarazi RC, Ferrario CM, Fighaly S, Alicandri C: Assessment of parasympathetic control of heart rate by a noninvasive method. Am J Physiol 1984;246:H838-842.

74 Berger RD, Saul JP, Cohen RJ: Transfer function analysis of autonomic regulation. I. Canine atrial rate response. Am J Physiol 1989;256:H142-152.

-75 Barnas MG, Boer WH, Koomans HA: Hemodynamic patterns and spectral analysis of heart rate variability during dialysis hypotension. J Am Soc Nephrol 1999;10:2577-2584.

-76 Zitt E, Neyer U, Meusburger E, Tiefenthaler M, Kotanko P, Mayer G, Rosenkranz AR: Effect of dialysate temperature and diabetes on autonomic cardiovascular regulation during hemodialysis. Kidney Blood Press Res 2008;31:217-225.

77 Chen SC, Chen CF, Huang JC, Lee MY, Chen JH, Chang JM, Hwang SJ, Chen HC: Link between peripheral artery disease and heart rate variability in hemodialysis patients. PloS One 2015;10:e0120459.

78 Chen SC, Huang JC, Tsai YC, Hsiu-Chin Mai RN, Jui-Hsin Chen RN, Kuo PL, Chang JM, Hwang SJ, Chen HC: Heart rate variability change before and after hemodialysis is associated with overall and cardiovascular mortality in hemodialysis. Sci Rep 2016;6:20597.

79 Ferrario M, Moissl U, Garzotto F, Cruz DN, Tetta C, Signorini MG, Ronco C, Grassmann A, Cerutti S, Guzzetti S: The forgotten role of central volume in low frequency oscillations of heart rate variability. PLoS One 2015;10:e0120167.

80 Dumaine RL, Montalescot G, Steg PG, Ohman EM, Eagle K, Bhatt DL: Renal function, atherothrombosis extent, and outcomes in high-risk patients. Am Heart J 2009;158:141-148.e1.

-81 Rajagopalan S, Dellegrottaglie S, Furniss AL, Gillespie BW, Satayathum S, Lameire N, Saito A, Akiba T, Jadoul M, Ginsberg N, Keen M, Port FK, Mukherjee D, Saran R: Peripheral arterial disease in patients with end-stage renal disease: Observations from the dialysis outcomes and practice patterns study (dopps). Circulation 2006;114:1914-1922.

82 Hasimu B, Li J, Nakayama T, Yu J, Yang J, Li X, Hu D: Ankle brachial index as a marker of atherosclerosis in chinese patients with high cardiovascular risk. Hypertens Res 2006;29:23-28.

83 Orchard TJ, Strandness DE Jr: Assessment of peripheral vascular disease in diabetes. Report and recommendations of an international workshop sponsored by the american heart association and the american diabetes association 18-20 september 1992, new orleans, louisiana. Diabetes Care 1993;16:11991209.

-84 O’Hare A, Johansen K: Lower-extremity peripheral arterial disease among patients with end-stage renal disease. J Am Soc Nephrol 2001;12:2838-2847.

85 O’Hare AM, Hsu CY, Bacchetti P, Johansen KL: Peripheral vascular disease risk factors among patients undergoing hemodialysis. J Am Soc Nephrol 2002;13:497-503.

-86 Chen SC, Chang JM, Hwang SJ, Tsai JC, Wang CS, Mai HC, Lin FH, Su HM, Chen HC: Significant correlation between ankle-brachial index and vascular access failure in hemodialysis patients. Clin J Am Soc Nephrol 2009;4:128-134.

87 Ono K, Tsuchida A, Kawai H, Matsuo H, Wakamatsu R, Maezawa A, Yano S, Kawada T, Nojima Y: Anklebrachial blood pressure index predicts all-cause and cardiovascular mortality in hemodialysis patients. J Am Soc Nephrol 2003;14:1591-1598.

88 Chen SC, Su HM, Chang JM, Liu WC, Tsai JC, Tsai YC, Lin MY, Hwang SJ, Chen HC: Increasing prevalence of peripheral artery occlusive disease in hemodialysis patients: A 2-year follow-up. Am J Med Sci 2012;343:440-445.

89 Chen SC, Chang JM, Liu WC, Huang JC, Chen YY, Yang TK, Su HM, Chen HC: Decrease in ankle-brachial index over time and cardiovascular outcomes in patients with hemodialysis. Am J Med Sci 2012;344:457-461.

-90 Leskinen Y, Salenius JP, Lehtimaki T, Huhtala H, Saha H: The prevalence of peripheral arterial disease and medial arterial calcification in patients with chronic renal failure: Requirements for diagnostics. Am J Kidney Dis 2002;40:472-479.

-91 Roman MJ, Ganau A, Saba PS, Pini R, Pickering TG, Devereux RB: Impact of arterial stiffening on left ventricular structure. Hypertension 2000;36:489-494. 


\section{Kidney \\ Blood Pressure Research}

Chen et al.: Prognostic Cardiovascular Markers in CKD

92 Su HM, Lin TH, Hsu PC, Chu CY, Lee WH, Chen SC, Lee CS, Voon WC, Lai WT, Sheu SH: Abnormally low and high ankle-brachial indices are independently associated with increased left ventricular mass index in chronic kidney disease. PloS One 2012;7:e44732.

$\$ 93$ Ix JH, Katz R, Peralta CA, de Boer IH, Allison MA, Bluemke DA, Siscovick DS, Lima JA, Criqui MH: A high ankle brachial index is associated with greater left ventricular mass mesa (multi-ethnic study of atherosclerosis). J Am Coll Cardiol 2010;55:342-349.

-94 Chen SC, Chang JM, Hwang SJ, Tsai JC, Liu WC, Wang CS, Lin TH, Su HM, Chen HC: Ankle brachial index as a predictor for mortality in patients with chronic kidney disease and undergoing haemodialysis. Nephrology (Carlton) 2010;15:294-299.

$\$ 95$ Matsumae T, Abe Y, Murakami G, Ishihara M, Ueda K, Saito T: Determinants of arterial wall stiffness and peripheral artery occlusive disease in nondiabetic hemodialysis patients. Hypertens Res 2007;30:377-385.

$\$ 96$ Shinohara K, Shoji T, Tsujimoto Y, Kimoto E, Tahara H, Koyama H, Emoto M, Ishimura E, Miki T, Tabata T, Nishizawa Y: Arterial stiffness in predialysis patients with uremia. Kidney Int 2004;65:936-943.

-97 Asmar R, Benetos A, Topouchian J, Laurent P, Pannier B, Brisac AM, Target R, Levy BI: Assessment of arterial distensibility by automatic pulse wave velocity measurement. Validation and clinical application studies. Hypertension 1995;26:485-490.

-98 Blacher J, Guerin AP, Pannier B, Marchais SJ, London GM: Arterial calcifications, arterial stiffness, and cardiovascular risk in end-stage renal disease. Hypertension 2001;38:938-942.

$\$ 99$ Tanaka H, Munakata M, Kawano Y, Ohishi M, Shoji T, Sugawara J, Tomiyama H, Yamashina A, Yasuda H, Sawayama T, Ozawa T: Comparison between carotid-femoral and brachial-ankle pulse wave velocity as measures of arterial stiffness. J Hypertens 2009;27:2022-2027.

100 Chung CM, Lin YS, Chu CM, Chang ST, Cheng HW, Yang TY, Hsiao JF, Pan KL, Hsu JT: Arterial stiffness is the independent factor of left ventricular hypertrophy determined by electrocardiogram. Am J Med Sci 2012;344:190-193.

101 Dellegrottaglie S, Sands RL, Gillespie BW, Gnanasekaran G, Zannad F, Sengstock D, Finkelstein F, Kiser M, Eisele G, Hinderliter AL, Levin NW, Cattan V, Saran R, Rajagopalan S: Association between markers of collagen turnover, arterial stiffness and left ventricular hypertrophy in chronic kidney disease (CKD): The renal research institute (rri)-ckd study. Nephrol Dial Transplant 2011;26:2891-2898.

102 Masugata H, Senda S, Hoshikawa J, Murao K, Hosomi N, Okuyama H, Inukai M, Himoto T, Nakatsuka Y, Imai M, Noma T, Kohno M, Goda F: Elevated brachial-ankle pulse wave velocity is associated with left ventricular hypertrophy in hypertensive patients after stroke. Tohoku J Exp Med 2010;220:177-182.

103 Hatsuda S, Shoji T, Shinohara K, Kimoto E, Mori K, Fukumoto S, Koyama H, Emoto M, Nishizawa Y: Regional arterial stiffness associated with ischemic heart disease in type 2 diabetes mellitus. J Atheroscler Thromb 2006;13:114-121.

104 Su HM, Lin TH, Hsu PC, Lee WH, Chu CY, Chen SC, Lee CS, Voon WC, Lai WT, Sheu SH: Association of bilateral brachial-ankle pulse wave velocity difference with peripheral vascular disease and left ventricular mass index. PloS One 2014;9:e88331.

105 Wei SY, Huang JC, Chen SC, Chang JM, Chen HC: Unequal arterial stiffness with overall and cardiovascular mortality in patients receiving hemodialysis. Am J Med Sci 2016;351:187-193.

106 Chen JH, Chen SC, Liu WC, Su HM, Chen CY, Mai HC, Chou MC, Chang JM: Determinants of peripheral arterial stiffness in patients with chronic kidney disease in southern taiwan. Kaohsiung J Med Sci 2009;25:366-373.

107 Kawamoto R, Kohara K, Tabara Y, Miki T, Ohtsuka N, Kusunoki T, Yorimitsu N: An association between decreased estimated glomerular filtration rate and arterial stiffness. Intern Med 2008;47:593-598.

108 Ohya Y, Iseki K, Iseki C, Miyagi T, Kinjo K, Takishita S: Increased pulse wave velocity is associated with low creatinine clearance and proteinuria in a screened cohort. Am J Kidney Dis 2006;47:790-797.

109 Ford ML, Tomlinson LA, Chapman TP, Rajkumar C, Holt SG: Aortic stiffness is independently associated with rate of renal function decline in chronic kidney disease stages 3 and 4. Hypertension 2010;55:1110-1115.

110 Taal MW, Sigrist MK, Fakis A, Fluck RJ, McIntyre CW: Markers of arterial stiffness are risk factors for progression to end-stage renal disease among patients with chronic kidney disease stages 4 and 5 Nephron Clin Pract 2007;107:c177-181.

111 Takenaka T, Mimura T, Kanno Y, Suzuki H: Qualification of arterial stiffness as a risk factor to the progression of chronic kidney diseases. Am J Nephrol 2005;25:417-424. 


\section{Kidney \\ Blood Pressure Research}

Chen et al.: Prognostic Cardiovascular Markers in CKD

112 Chen SC, Chang JM, Liu WC, Tsai YC, Tsai JC, Hsu PC, Lin TH, Lin MY, Su HM, Hwang SJ, Chen HC: Brachialankle pulse wave velocity and rate of renal function decline and mortality in chronic kidney disease. Clin J Am Soc Nephrol 2011;6:724-732.

113 Clark CE, Campbell JL, Evans PH, Millward A: Prevalence and clinical implications of the inter-arm blood pressure difference: A systematic review. J Hum Hypertens 2006;20:923-931.

114 Williams B, Poulter NR, Brown MJ, Davis M, McInnes GT, Potter JF, Sever PS, Mc GTS: Guidelines for management of hypertension: Report of the fourth working party of the british hypertension society, 2004bhs iv. J Hum Hypertens 2004;18:139-185.

115 Clark CE, Taylor RS, Shore AC, Ukoumunne OC, Campbell JL: Association of a difference in systolic blood pressure between arms with vascular disease and mortality: A systematic review and meta-analysis. Lancet 2012;379:905-914.

$\$ 116$ Clark CE, Campbell JL, Powell RJ: The interarm blood pressure difference as predictor of cardiovascular events in patients with hypertension in primary care: Cohort study. J Hum Hypertens 2007;21:633-638.

117 Clark CE, Powell RJ: The differential blood pressure sign in general practice: Prevalence and prognostic value. Fam Pract 2002;19:439-441.

118 Clark CE, Taylor RS, Shore AC, Campbell JL: The difference in blood pressure readings between arms and survival: Primary care cohort study. BMJ 2012;344:e1327.

119 Su HM, Lin TH, Hsu PC, Chu CY, Lee WH, Chen SC, Lee CS, Voon WC, Lai WT, Sheu SH: Association of interarm systolic blood pressure difference with atherosclerosis and left ventricular hypertrophy. PloS One 2012;7:e41173.

120 Sheng CS, Liu M, Zeng WF, Huang QF, Li Y, Wang JG: Four-limb blood pressure as predictors of mortality in elderly chinese. Hypertension 2013;61:1155-1160.

121 Chen SC, Chang JM, Tsai YC, Tsai JC, Su HM, Hwang SJ, Chen HC: Association of interleg bp difference with overall and cardiovascular mortality in hemodialysis. Clin J Am Soc Nephrol 2012;7:1646-1653.

122 Chen SC, Tsai YC, Huang JC, Lee SC, Chang JM, Hwang SJ, Chen HC: Interankle systolic blood pressure difference and renal outcomes in patients with chronic kidney disease. Nephrology (Carlton) 2016;21:379386.

123 Raggi P, Boulay A, Chasan-Taber S, Amin N, Dillon M, Burke SK, Chertow GM: Cardiac calcification in adult hemodialysis patients. A link between end-stage renal disease and cardiovascular disease? J Am Coll Cardiol 2002;39:695-701.

124 Cho IJ, Chang HJ, Park HB, Heo R, Shin S, Shim CY, Hong GR, Chung N: Aortic calcification is associated with arterial stiffening, left ventricular hypertrophy, and diastolic dysfunction in elderly male patients with hypertension. J Hypertens 2015;33:1633-1641.

125 Guerin AP, London GM, Marchais SJ, Metivier F: Arterial stiffening and vascular calcifications in end-stage renal disease. Nephrol Dial Transplant 2000;15:1014-1021.

126 Wanner C, Amann K, Shoji T: The heart and vascular system in dialysis. Lancet 2016;388:276-284.

127 Ogawa T, Ishida H, Matsuda N, Fujiu A, Matsuda A, Ito K, Ando Y, Nitta K: Simple evaluation of aortic arch calcification by chest radiography in hemodialysis patients. Hemodial Int 2009;13:301-306.

128 Lee CT, Huang CC, Hsu CY, Chiou TT, Ng HY, Wu CH, Kuo WH, Lee YT: Calcification of the aortic arch predicts cardiovascular and all-cause mortality in chronic hemodialysis patients. Cardiorenal Med 2014;4:34-42.

129 Lee MJ, Shin DH, Kim SJ, Oh HJ, Yoo DE, Ko KI, Koo HM, Kim CH, Doh FM, Park JT, Han SH, Yoo TH, Choi KH, Kang SW: Progression of aortic arch calcification over 1 year is an independent predictor of mortality in incident peritoneal dialysis patients. PloS One 2012;7:e48793.

130 Fujiu A, Ogawa T, Matsuda N, Ando Y, Nitta K: Aortic arch calcification and arterial stiffness are independent factors for diastolic left ventricular dysfunction in chronic hemodialysis patients. Circ J 2008;72:1768-1772.

131 Shin MC, Lee MY, Huang JC, Tsai YC, Chen JH, Chen SC, Chang JM, Chen HC: Association of brachial-ankle pulse wave velocity and cardiomegaly with aortic arch calcification in patients on hemodialysis. Medicine 2016;95:e3643.

132 Dao HH, Essalihi R, Bouvet C, Moreau P: Evolution and modulation of age-related medial elastocalcinosis: Impact on large artery stiffness and isolated systolic hypertension. Cardiovasc Res 2005;66:307-317.

133 McEniery CM, McDonnell BJ, So A, Aitken S, Bolton CE, Munnery M, Hickson SS, Yasmin, Maki-Petaja KM, Cockcroft JR, Dixon AK, Wilkinson IB: Aortic calcification is associated with aortic stiffness and isolated systolic hypertension in healthy individuals. Hypertension 2009;53:524-531. 


\section{Kidney Blood Pressure Research}

134 An WS, Son YK, Kim SE, Kim KH, Yoon SK, Bae HR, Rha SH: Vascular calcification score on plain radiographs of the feet as a predictor of peripheral arterial disease in patients with chronic kidney disease. Int Urol Nephrol 2010;42:773-780.

135 Adragao T, Pires A, Branco P, Castro R, Oliveira A, Nogueira C, Bordalo J, Curto JD, Prata MM: Ankle--brachial index, vascular calcifications and mortality in dialysis patients. Nephrol Dial Transplant 2012;27:318-325.

136 Chen SC, Lee MY, Huang JC, Shih MC, Chang JM, Chen HC: Association of ankle-brachial index and aortic arch calcification with overall and cardiovascular mortality in hemodialysis. Sci Rep 2016;6:33164.

137 Rayner BL, Goodman H, Opie LH: The chest radiograph. A useful investigation in the evaluation of hypertensive patients. Am J Hypertens 2004;17:507-510.

138 Li LC, Lee YT, Lee YW, Chou CA, Lee CT: Aortic arch calcification predicts the renal function progression in patients with stage 3 to 5 chronic kidney disease. Biomed Res Int 2015;2015:131263. 